\title{
PROMISCUIDAD, FAMILIA Y DOCENCIA: LAS TENSIONES ENTRE DISIDENCIA Y NORMALIZACIÓN SEXUAL EN TAXI AL W.C. DE FRANK RIPPLOH
}

\author{
Promiscuity, Family and Teaching: The Tensions between Sexual Dissidence and Sexual \\ Normalization in Taxi to the Toilet by Frank Ripploh
}

Atilio RAÚl RUBino ${ }^{a}$

Universidad Nacional de La Plata / CONICET

DOI: $10.15366 /$ secuencias2020.51.004

\section{RESUMEN}

Me interesa indagar las tensiones entre disidencia sexual y homonorma en una película clave para la disidencia sexual en Alemania, Taxi al W.C. (1980), de Frank Ripploh. Pensar la sexualidad en términos de disidencia implica tener presente que siempre esta se da respecto de una norma. En el caso de la película de Ripploh se trata de una norma interna a la comunidad gay, una incipiente homonormatividad. De esta forma, se plantean los modos de vida vivibles para un Schwul de los ochenta y las formas de vida ininteligibles y, por eso, abyectas. La doble vida que el personaje autoficcional de Ripploh lleva adelante - una vida íntima como homosexual promiscuo y una vida social como maestro de escuela - se complejiza convirtiéndose en una triple vida -maestro de escuela, Schwul promiscuo y gay monógamo-. La película de Ripploh presenta una serie de prácticas disidentes y promiscuas y lo hace de forma explícita: baños públicos, saunas, cines, exhibición de cuerpos, BDSM, lluvia dorada, pornografía, deseo sexual infantil. Estas prácticas se ven tensionadas con una incipiente asociación de la promiscuidad disidente con el posible contagio de enfermedades, que se adelanta a la crisis del VIH-SIDA y al uso biopolítico de la enfermedad. De esta forma, siguiendo a Deleuze y Guattari, podemos resignificar la idea de enfermedad para pensar en el contagio vampírico, como una transmisión monstruosa-disidente que se opone a la filiación familiar. Así, la salida pública del armario por parte tanto del personaje autoficcional como del propio director, protagonista y guionista puede pensarse como un contagio disidente que - a diferencia de la filiación familiar- contrarresta la producción de normalidad del Hetero Capitalismo Mundial Integrado.

Palabras clave: Frank Ripploh, Taxi al W.C., disidencia sexual, Estudios Queer, cine alemán

\section{ABSTRACT}

I am interested in analyzing the tensions between sexual dissidence and homonormativity in a film that was key to the sexual dissidence in Germany, Taxi zum Klo (1980) by Frank Ripploh. Seeing sexuality in terms of dissidence implies bearing in mind that it always takes place regarding a norm. In the case of the film by Ripploh, it is a norm that belongs to the gay community, an emergent homonormativity. Accordingly, the film shows the ways of life that can be lived in a 1980 s Schwul and the intelligible -thus, heinous- ways of life. The double life of Ripploh's autofictional character, who leads an intimate life as a promiscuous homosexual and a social life as a schoolteacher, become even more complex in a triple life: schoolteacher, promiscuous Schwul and monogamous gay man. Ripploh's film shows a series of dissident and promiscuous practices, and it does so in an explicit manner: public restrooms, saunas, cinemas, the exhibition of the bodies, BDSM, golden shower, pornography, children's sexual desire. These practices are put into tension with a budding connection between dissident promiscuity and the possible contagion of diseases, which comes ahead of time from the HIV/AIDS crisis and the biopolitical use of the disease. This way, following Deleuze and Guattari, we can redefine the idea of disease in order to think of vampirical contagion as a monstrous-dissident transmission that is opposed to family filiation. Therefore, the public coming-out by the character as well as by the director/main character/ screenwriter himself can be seen as a dissident contagion that - unlike family filiation - counteracts the production of the Integrated World Hetero-Capitalistic normality.

Keywords: Frank Ripploh, Taxi to the Toilet, Sexual Dissidence, Queer Studies, German Cinema

[a] Atilio Raúl Rubino es profesor y Doctor en Letras por la Facultad de Humanidades y Ciencias de la Educación de la Universidad Nacional de La Plata (FaHCE-UNLP), Buenos Aires, Argentina. Su Tesis Doctoral trató sobre las representaciones de la disidencia sexual en la literatura y el cine de habla alemana. Ha dictado seminarios sobre literatura y cine y sobre género y sexualidad y ha publicado contribuciones sobre los mismos temas en revistas científicas y libros especializados. Actualmente se desempeña como Ayudante Diplomado en la Cátedra de Introducción a la Literatura (FaHCE-UNLP), como becario postdoctoral del Consejo Nacional de Investigaciones Científicas y Técnicas (CONICET) y como investigador en formación del Instituto de Investigaciones en Humanidades y Ciencias Sociales (IdIHCS - UNLP/CONIET). E-mail: atiliorubino@yahoo.com.ar 


\section{Introducción}

Taxi al W.C. (Taxi zum Klo, Taxi to the Toilet, Frank Ripploh, 1980) es una de las películas clave para la disidencia sexual ${ }^{1}$ de los ochenta en Alemania y Europa. Realizada con un bajo presupuesto y de forma independiente - Frank Ripploh no solo la dirige y protagoniza, sino que además es responsable del guion-, se ha convertido con el tiempo en un filme de culto, ya que es una de las películas que, para la época, representa de forma más explícita las relaciones homosexuales y, asimismo, porque en ella se pueden encontrar muchas problematizaciones internas a la comunidad gay que luego serán características de las discusiones de la segunda mitad de la década de los ochenta y principios de los noventa entre las perspectivas de la liberación gay-lésbica y la emergente teoría queer.

Estrenada en 1980, se encuentra en una época clave de cambio en las representaciones disidentes en el cine, entre la liberación de los setenta y lo queer de los noventa. Para Alberto Mira, 1980 representa un año que es «la línea divisoria entre dos épocas» ${ }^{2}$, pues comienza a desarrollarse "una nueva voz homosexual que se proyecta en el cine independiente y de arte y ensayo» ${ }^{3}$. Aunque Mira se refiere fundamentalmente a iQue no pare la música! (Can't Stop the Music, Nancy Walker, 1980), American Gigolo (Paul Schrader, 1980) y A la caza (Cruising, William Friedkin, 1980) y se ocupa solo sucintamente de Taxi al W.C.. Para Vito Russo se trata del primer filme post liberación gay ${ }^{4}$, ya que este «ignora las cuestiones políticamente correctas sobre la "imagen gay positiva" que algunos activistas gays querían proyectar en el

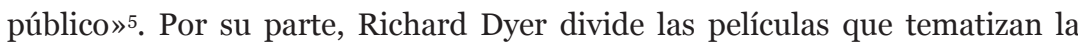
cultura gay de la época en institucionales, de afirmación del movimiento de liberación gay-lésbico y confrontativas. Para Dyer, Taxi al W.C. constituye «el filme confrontativo más internacional y comercialmente exitoso» ${ }^{6}$. Por otro lado, habría que considerarla como continuadora de la trayectoria iniciada por películas como No es perverso ser homosexual, perverso es el contexto (Nicht der Homosexuelle ist pervers, sondern die Situation, in der er lebt, It Is Not the Homosexual Who Is Perverse, But the Society in Which He Lives, Rosa von Praunheim, 1971) o La ley del más fuerte (Faustrecht der Freiheit, Fox and His Friends, Rainer Werner Fassbinder, 1975). Fassbinder, Praunheim y Werner Schroeter son probablemente los directores de cine disidente más importantes de los setenta en la República Federal de Alemania y que, de distintas maneras, evitaron caer en las representaciones políticamente correctas sobre la homosexualidad. Mi interés en la película de Ripploh radica justamente en que no ha recibido tanta atención de la crítica. En consecuencia, en este artículo me interesa abordar el análisis de la película de Ripploh con mayor profundidad para pensarla, justamente, en ese período intermedio entre dos épocas, que podríamos llamar como la década de la liberación gay-lésbica y la que significó la emergencia de la teoría y la perspectiva queer.
[1] Por disidencia me refiero a aquellas manifestaciones de sexualidad que cuestionan el régimen heteronormativo y la matriz heterosexual. Hablar de sexualidades disidentes permite, así, entrar en la dinámica de los dispositivos de poder, control y producción de cuerpos sexuados que están en juego. Pensar la sexualidad en términos de disidencia implica tener presente que siempre esta se da respecto de una norma; en el caso de la película de Ripploh se trata de una norma interna a la comunidad gay, una incipiente homonormatividad. Para una discusión sobre el concepto de disidencia sexual y su utilización en el análisis de la cultura. Atilio Raúl Rubino, «Hacia una (in)definición de la disidencia sexual. Una propuesta para su análisis en la cultura» (Revista Luthor [entender, destruir $y$ crear], n. ${ }^{\circ} 39$, vol. IX, febrero, 2019).

[2] Alberto Mira, Miradas insumisas. Gays y lesbianas en el cine (Barcelona/Madrid, Egales, 2008), p. 360.

[3] Alberto Mira, Miradas insumisas, p. 365.

[4] Vito Russo, The Celluloid Closet: Homosexuality in the Movies. Revisited Edition (Nueva York, Harper \& Row, 1995), p. 238.

[5] Vito Russo, The Celluloid Closet, p. 187. (La traducción es mía).

[6] Richard Dyer, Now You See it: Studies on Lesbian and Gay Film (Londres/Nueva York, Routledge, 2007), p. 205. (La traducción es mía). 


\section{Disidencia sexual entre los setenta y los noventa}

[7] Annamarie Jagose, Queer Theory: An Introduction (Nueva York, New York University Press, 1996), p. 36.

[8] Paul B. Preciado, «Terror anal: apuntes sobre los primeros días de la revolución sexual», en El deseo homosexual (con Terror anal) (Barcelona, Melusina, 2009), p. 157.

[9] Javier Sáez, «El contexto sociopolítico de surgimiento de la teoría queer. De la crisis del sida a Foucault», en David Córdoba, Javier Sáez y Francisco Vidarte (eds.), Teoría queer: políticas bolleras, maricas, trans, mestizas (Barcelona/ Madrid, Egales, 2005), p. 67.

[10] Michael Holy, «Jenseits von Stonewall - Rückblicke auf die Schwulenbewegung in der BRD 1969-1980", en Andreas Pretzel y Volker Weiß (eds), Rosa Radikale. Die Schwulenbewegung der 1970er Jahre (Hamburgo, Männerschwarm Verlag, 2012), p. 62.

[11] Michael Holy, «Jenseits von Stonewall», p. 63.

[12] David Halperin, «The Normalization of Queer Theory» (Journal of Homosexuality, vol. 45, n. $^{\circ}$ 2-3-4, 2003), p. 339-340.
Según la visión más hegemónica de la historia de la disidencia sexual, con la rebelión de Stonewall en Estados Unidos en 1969 -y de la mano de los movimientos feministas - surgen los movimientos de liberación gay-lésbica y el modelo de identidad gay, de proyecciones y características globales. La creciente normalización de lo gay-lésbico hacia mediados de los años ochenta y el silenciamiento de la epidemia global de VIH-SIDA provocaron la crisis de este modelo. En ese marco, lo queer, nacido en el activismo, pero con una fuerte y rápida impronta en la academia - con un pensamiento posteriormente enunciado como teoría queer-, se constituye como una forma de confrontación contra la normalización gay-lésbica y el silencio político y social ante la catástrofe del VIH-SIDA. Sin embargo, esta es una visión acotada de la historia de la disidencia, que mira lo ocurrido sobre todo en Estados Unidos (Stonewall y la Queer Theory). Como comenta Jagose, la liberación gay no fue un movimiento social coherente ni monolítico ${ }^{7}$. Es importante tener en cuenta que la ruptura epistemológica que significó la perspectiva queer norteamericana de los noventa ya se estaba gestando en Europa desde los setenta ${ }^{8}$. En la República Federal de Alemania, el año de la rebelión de Stonewall también resulta clave, pues en 1969 se lleva a cabo la despenalización parcial de la ley que prohibía las relaciones sexuales entre hombres (el parágrafo 175 del código penal). Este hecho posibilitó las primeras organizaciones militantes que conformarían la Schwulenwebegung de los años setenta (el movimiento de liberación gay de la República Federal de Alemania).

Javier Sáez señala como inicio de lo queer la confluencia de diversas crisis en la década de los ochenta «que van a dar un giro radical a las políticas feministas y de los grupos de gays y lesbianas: la crisis del VIH-SIDA, la crisis del feminismo heterocentrado, blanco y colonial y la crisis cultural derivada de la asimilación por el sistema capitalista de la incipiente cultura gay»9. En el caso de Alemania, el período 1976-1979 de la Schwulenwebegung puede ser considerado, según Holy, como "Amerikanisierung» ${ }^{10}$. Para Holy, a partir de 1977 comienza en Alemania la mayor influencia transnacional del movimiento de liberación gay norteamericano, a partir de la fascinación por Stonewall y el American Way of Life ${ }^{11}$. Hacia los ochenta, se genera un cambio de paradigma, ya que comienza una clara normalización gay con la inclusión de políticas de corte integracionista dentro de las instituciones.

Como es sabido, el sintagma «teoría queer» surge primero como un chiste de la mano de Teresa de Lauretis, quien lo utiliza por primera vez en una conferencia en la Universidad de California en 1990. Pero este uso, por un lado, armoniza muy bien con la crítica a la política identitaria gay-lésbica ${ }^{12} \mathrm{y}$, por otro, propone una línea postidentitaria más acorde al auge del postestructuralismo. De esta forma, la teoría queer cristaliza una visión homogénea del pasado de la militancia de los años setenta que borra algunas de sus complejidades y disputas internas. Si bien la identidad gay de los setenta fue leída desde 
la teoría queer como esencialista, era en muchos casos una estrategia política de visibilización y de lucha contra el sistema heteronormativo ${ }^{13}$. Según Jagose, la identidad gay fue en su momento revolucionaria, ya que no buscaba el reconocimiento social, sino el derrumbe de las instituciones sociales que marginalizaban y patologizaban la homosexualidad ${ }^{14}$. Se trataba de una oposición al sistema, pues se consideraba que nunca sería transformado si se buscaba pertenecer a él. En este sentido es que, como se dijo, muchas de las novedades que significarían las perspectivas queer de los noventa ya se pueden encontrar en los años setenta, fundamentalmente en la militancia y el arte europeos. Paul B. Preciado considera que en los setenta en Europa comienza

un proceso de fragmentación y de desplazamiento que pone en cuestión la afirmación de un único sujeto feminista y de un único sujeto homosexual... un proceso muy similar al que tendrá lugar en la década de los ochenta en el feminismo y los movimientos homosexuales americanos y que dará lugar a los movimientos queer. Se dibujan ya las que serán para el resto del siglo las dos vías de acción política que emergen de los movimientos de izquierda: revolución o normalización ${ }^{15}$.

Justamente este tipo de cuestiones que se anticipan a los Estudios Queer que se institucionalizan en los años noventa - y Preciado ve en textos activistas y teórico-políticos europeos de los setenta- también las podemos encontrar tensionadas en películas como Taxi al W.C. de Frank Ripploh.

\section{Taxi al W.C. entre dos épocas}

Si bien Taxi al W.C. constituye una película clave para la disidencia sexual, no ha sido suficientemente abordada por la crítica especializada. Me interesa justamente indagarla a partir de la tensión entre la disidencia sexual y la homonorma. Pensar la sexualidad en términos de disidencia implica tener presente que siempre esta se da respecto de una norma. En el caso de la película de Ripploh se trata no solo de la norma heterosexual, sino también de la interna a la comunidad gay. Lisa Duggan retoma el término heteronormatividad de Warner ${ }^{16}$ para hablar también de la existencia de una homonormatividad a la que define como «una política que no impugna los supuestos y las instituciones heteronormativos dominantes, sino que los respalda y sostiene, mientras promete la posibilidad de un electorado gay desmovilizado y privatizado, una cultura gay despolitizada anclada en el consumo y la domesticidad $»^{17}$. Si tomamos este concepto se puede pensar que Taxi al W.C. da cuenta de ciertas tensiones entre liberación y normalización. De esta forma, se plantean los modos de vida vivibles para un $S c h w u l^{18}$ de los ochenta y las formas de vida ininteligibles y, por eso, abyectas.

Taxi al W.C. de Frank Ripploh puede ser considerada una película autoficcional, ya que su protagonista es el propio director y guionista haciendo de sí mismo. Frank Ripploh es un maestro de escuela (Hauptschule) que lleva
[13] Annamarie Jagose, Queer Theory, p. 38 .

[14] Annamarie Jagose, Queer Theory, p. 37.

[15] Paul B. Preciado, «Terror anal», p. 147. Asimismo, Preciado considera que «los textos inaugurales de la teoría queer tendrán innumerables puntos comunes con los textos de Guy Hocquenghem y del FHAR: uso de la injuria (queer, homosexual, marica, bollera) como eje de enunciación y de producción de saber, crítica de la normalización heterosexual, desplazamiento de las oposiciones tradicionales hombre/mujer, hetero/homosexual, elaboración de una teoría compleja de la opresión que incluya los ejes de raza, edad, discapacidad...». Paul B. Preciado, «Terror anal», p. 150.

[16] Michael Warner, «Introduction», en Fear of a Queer Planet: Queer Politics and Social Theory (Minneapolis, University of Minnesota Press, 1993), pp. VII-XXXI.

[17] Lisa Duggan, The Twilight of Equality? Neoliberalism, Cultural Politics, and The Attack on Democracy (Boston, Beacon Press, 2003), p. 50. (La traducción es mía).

[18] La palabra Schwul en Alemania es el término con el que se autoproclaman las identidades disidentes a partir de los años setenta. Así como «queer», palabra con la que convive después de los noventa, se trata de un insulto resignificado, que puede ser traducido como «puto». 


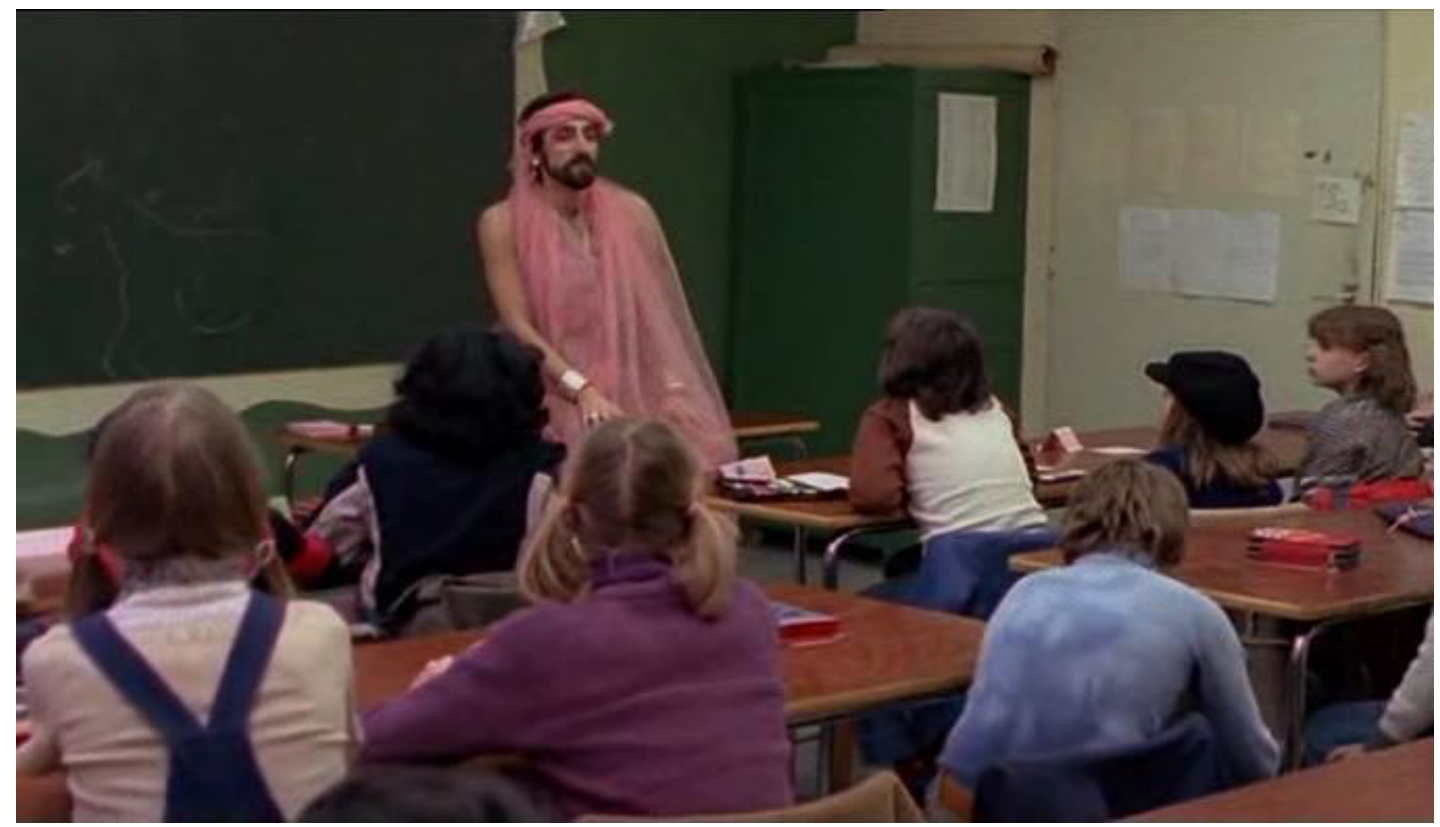

Frank Ripploh montado como Peggy von Schnottgenberg al final de la película en el aula de la escuela en la que es docente. Fotograma de Taxi al W.C (Frank Ripploh, 1980).

[19] Entiendo a la promiscuidad en un sentido positivo, como un agenciamiento de la propia sexualidad que luego será atacado a partir del giro conservador que genera la crisis del VIH-SIDA en los ochenta.

[2o] Glory Hole (que podría traducirse por «agujero glorioso») es el anglicismo para indicar los baños públicos con agujeros en las paredes de los cubículos, por donde se puede introducir el pene para tener sexo con quien está del otro lado. Se trata de una forma de sexo casual propia del cruising en baños públicos y saunas que se constituye como una forma de sociabilidad en épocas en donde la homosexualidad no podía hacerse. Para Foucault, el sexo en los baños tenía una importancia política que tendía a la desubjetivación porque lo

que había ahí no eran más que cuerpos o partes de cuerpos, despersonalizados, produciendo formas de placer nuevas e inesperadas. Michel Foucault, «The Gay Science» (Critical Inquiry, n. ${ }^{\circ}$ 37, vol. 3, 2011), p. 399.

[21] Alberto Mira, Miradas insumisas, p. 376. una vida homosexual activa $-\mathrm{o}$, podríamos decir, representada como promiscua- ${ }^{19}$. Aunque estas dos facetas de su vida, la profesional y la personal, están separadas, a veces se entremezclan. En una de las escenas iniciales, por ejemplo, lo vemos revisando trabajos de sus alumnos en un glory hole ${ }^{20}$, mientras espera tener sexo casual. Una noche conoce a Bernd, interpretado por su pareja en la vida real, Bernd Broaderup, con quien comienza una relación estable, sin dejar de seguir adelante con su vida de promiscuidad. Pero es justamente esto lo que genera el conflicto en la película, la posibilidad de construir una relación sexo-afectiva no monogámica y, en este sentido, no siguiendo los cánones de las relaciones heterosexuales y de la familia nuclear burguesa. La doble vida que lleva adelante - una vida íntima como homosexual promiscuo y una vida social como maestro de escuela- se complejiza convirtiéndose en una triple vida: maestro de escuela, Schwul promiscuo y gay monógamo.

Para Alberto Mira, esta trama es comparable con la de un filme inglés dos años anterior, Nighthawks (Ron Peck, 1978) que, según él, «buscaba la normalización de la homosexualidad, restándole drama» y en donde «los avatares de la promiscuidad se presentan como una realidad cotidiana sin consecuencias demasiado dolorosas» ${ }^{21}$. Para Mira, la película de Ripploh es similar, solo que 
en ella «se produce la impresión de que ser homosexual promiscuo es divertido y placentero ${ }^{22}$. Jim, el protagonista de la película de Peck, también lleva una doble vida como docente de escuela secundaria y recorriendo distintos bares gay de la noche londinense. Solo que en Nighthawks lo que prevalece es cierta sensación de soledad al no poder conformar una relación estable. Como comenta Chris O’Rourke, «el patrón cíclico de la vida de Jim en la escena comercial también incrementa la impresión de que está atrapado en el circuito pub-club-disco ${ }^{23}$ como si otra forma de vida no fuera posible. Se cuestiona así, según O’Rourke, la cultura del consumo y el mercado gay ${ }^{24}$.

La película de Ripploh no finaliza con una resolución al conflicto de la doble vida de Frank, sino, como en Nighthawks, con la salida pública del armario en el ámbito laboral, pero de una forma mucho más disidente. Después de una noche en una Tuntenball, una celebración Schwul disidente drag ${ }^{25}$, Ripploh se separa de Bernd y asiste, sin dormir, a su trabajo frente al aula vestido como mujer, dragueado, como una princesa u odalisca con vestido y velo rosa. La cuestión de la doble vida de Nighthawks en Taxi al W.C. no solo se lleva al extremo, sino que se convierte en el trasfondo para un nuevo conflicto: ¿qué vida llevar adelante? ¿una vida homosexual implica ajustarse a los mismos cánones y parámetros de las relaciones heterosexuales, de la familia nuclear?

Tanto Vito Russo como Richard Dyer, entre otros, coinciden en que los filmes de tema disidente se reapropian de los estereotipos de la cultura mayoritaria sobre las minorías. En este sentido, como comenta Jones, la película de Ripploh propone un quiebre bastante importante respecto al cine de temática homosexual al integrar los estereotipos y paradigmas, pero para subvertirlos ${ }^{26}$. De esta forma, Ripploh no solo plantea una situación que resulta un conflicto interno a la comunidad gay y la relación con la normatividad, sino que también la enunciación es claramente disidente: su propia voz, con sus dudas, sus deseos, sus placeres, es la que aparece en primer plano, por un lado, por el uso de la voz en off, pero también, por otro, por el registro autoficcional. Así, la película de Ripploh presenta una serie de prácticas disidentes y promiscuas y lo hace de forma explícita: baños públicos, saunas, cines, exhibición de cuerpos, BDSM $^{27}$, lluvia dorada ${ }^{28}$, pornografía, deseo sexual infantil. Estas escenas
[22] Alberto Mira, Miradas insumisas, p. 377 .

[23] Chris O'Rourke, «Queer London on Film: Victim (1961), The Killing of Sister George (1968) and Nighthawks (1978)», en Pam Hirsch y Chris O'Rourke (eds.), London on Film (Suiza, Palgrave Macmillan, 2017), p. 126. (La traducción es mía).

[24] Chris O'Rourke, «Queer London», p. 126.

[25] Tuntenball puede traducirse por baile de locas o hadas. La palabra «Tunte» en alemán designa al homosexual afeminado. Este tipo de fiestas tienen una amplia tradición en Alemania y se trata de celebrar la feminidad de los varones homosexuales; en este sentido, implica también una fuerte oposición a un tipo de homosexualidad masculina que ostenta la virilidad. En los setenta en Alemania se generó una fuerte disputa en el seno del movimiento Schwul en torno a la representatividad del movimiento. Así, «Tunte» se convirtió en un tipo de enunciación identitaria que, como parte de la enunciación Schwul, esgrimía la necesidad de que los varones homosexuales se pudieran emancipar del disciplinamiento de género sexual.

[26] James Jones, «History and Homosexuality in Frank Ripploh's Taxi to the Toilet», en Christoph Lorey y John Plews, Queering the Canon: Defying Sights in German Literature and Culture (Columbia, Camden House, 1998) p. 342.

[27] El término sadomasoquismo nace en el ámbito de la medicina y la psiquiatría para designar a una desviación patológica de la conducta sexual. En los años setenta, con los grupos y subculturas en torno a estas prácticas sexo-disidentes, se comienza a usar la sigla SM o S\&M para desligarla de las connotaciones negativas del término «sadomasoquismo». Luego se convirtió en BDSM (Bondage, Disciplina, Dominación, Sumisión, Sadismo y Masoquismo) y también BDSM-leather -o «BDSM-Leder» en alemán-, por la asociación con el uso de ropa de cuerpo.

[28] Es la práctica sexual de orinar sobre otra persona. Si bien se trata de una práctica en la que usan los genitales, no necesariamente se hace con sus funciones sexuales. Al mismo tiempo, sí consiste en una práctica desgenitalizada para la persona orinada. Este tipo de prácticas, como el fistfucking, se asocian con el BDSM y tienen, para la cultura gay-lésbica de los años setenta, una dimensión política de búsqueda de nuevos placeres que rompan con el disciplinamiento sexual y corporal: «mediante la invención de placeres corporales nuevos, intensos y difusos, la cultura queer ha producido una inversión táctica de los mecanismos de la sexualidad, haciendo un uso estratégico de las diferencias de poder, de las sensaciones físicas y las categorías de identidad sexual, a fin de crear una praxis queer que finalmente prescinda de la sexualidad y desestabilice la constitución de la identidad misma». David Halperin, San Foucault: para una hagiografía gay (Buenos Aires, El cuenco de plata, 2007), p. 119-120. 
[29] James Jones, «History and Homosexuality», p. 342.

[3o] En este sentido se puede contrastar con otra película clave del cine homosexual alemán, La consecuencia (Die Konsequenz, The Consequence, Wolfgang Petersen, 1977), basada en la novela homónima de Alexander Ziegler de 1975. El tema aquí claramente no tiene que ver con el descubrimiento o la producción de nuevos placeres, ni siquiera con el sexo, sino que, más bien, se trata de una historia de amor.

[31] Paul B. Preciado, «Terror anal», p. 163. desafían los estereotipos fílmicos de la homosexualidad al oponerse a eliminar las escenas sexuales ${ }^{29}$ y hacerlas explícitas, así como al poner la sexualidad, más que el amor, como el tema de la película ${ }^{30}$. A su vez, muestra los rituales de cruising, pero también de la vida homosexual.

Ya desde la escena inicial, la película inscribe a Frank en la Schwulenbewegung y, con ello, se ubica justamente con posterioridad a la militancia de los setenta. Vemos en su pared una serie de fotos, tarjetas, pines, etc. que dan cuenta de un pasado reciente del personaje no solo en el ambiente gay, sino también particularmente disidente. Es decir, se trata del pasado personal de Frank, pero también del movimiento de liberación alemán de los setenta. En ese marco, lo que ocurre en la película puede ser pensado como un paso más después de la liberación de los setenta, así como la continuación de ciertos paradigmas no solo sobre la homosexualidad, sino también sobre la disidencia -y la normalización gay ya más clara para los años ochenta-. La pregunta que parece sobrevolar es qué tipo de vida puede llevar adelante una persona homosexual. Si la diversidad es ahora aceptada, ¿es posible llevar una vida disidente? ¿O para seguir siendo aceptado hay que someterse a ciertas reglas normalizadoras de la familia nuclear? O, dicho a través de Preciado, «¿́cómo evitar el marketing anal? ¿Cómo sobrevivir a los efectos normalizantes de las políticas de la identidad? ¿Cómo sobrevivir con el ano colectivo y abierto?» ${ }^{31}$.

En efecto, la película parece ubicarse en la encrucijada de dos épocas, parece estar a caballo entre los setenta y los ochenta. En este sentido, la doble vida que mantiene Frank, como docente y como homosexual que lleva adelante una vida promiscua, se solapa con la necesidad de formar una familia y llevar adelante una vida de pareja homonormativa, que es algo que resulta insatisfactorio para el personaje. Si salir de los baños y tomar las calles es algo que ya se ha conquistado, esto implica cierta hipocresía en el sentido de que si se acepta la homosexualidad se lo hace como una identidad a la que se le exige decencia para formar parte del sistema. Se podría decir: se acepta la homosexualidad, pero no la disidencia. La doble vida inicial de Frank ahora es claramente triple, pues la relación de pareja está tensionada entre la monogamia y la promis-
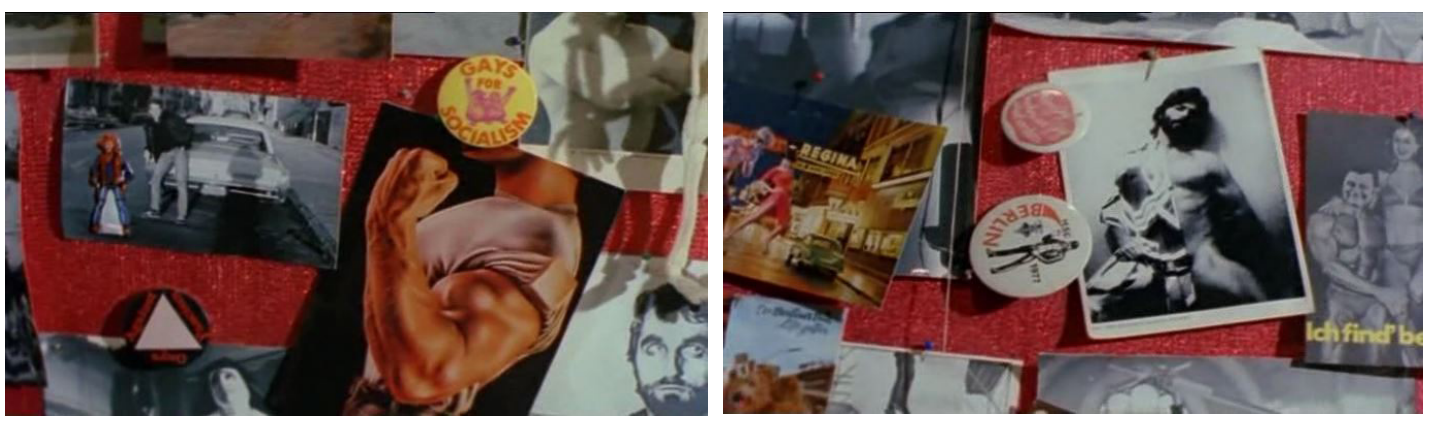

Collage de imágenes en la pared de Frank, que lo ubican en el marco de la militancia Schwul de los años setenta en Alemania. Fotograma de Taxi al W.C. 
cuidad. Se trata de un tema que era importante para la comunidad gay de los años setenta y ochenta, pues implicaba pensar los estilos de vida posibles, qué modelos seguir, qué prácticas resultaban disidentes y, con ello, negadas o censuradas por la sociedad en general.

Jones comenta que «Ripploh conceptualiza este tema de la monogamia versus promiscuidad en parte como un constructo histórico» ${ }^{32}$. Frank no quiere ser como los heterosexuales, eso es lo que le dice a Bern en una de sus discusiones. El hecho de que ahora esté permitido salir del armario, el hecho de que ya no sea penado por la ley, no implica para él que deba llevar adelante una vida igual a la de la familia heterosexual. Bern quiere que se vayan a vivir a una granja, alejados de la ciudad, piensa que Frank podría trabajar ahí, podrían adoptar niños y formar una familia. En la perspectiva de Bern, aparece así cierta utopía gay residual, que tiene más que ver con imaginarios de épocas anteriores, en las que todavía no se podía llevar una vida homosexual abiertamente y, por eso, una posibilidad de felicidad era apartarse de la ciudad, en donde nadie pueda prohibirles esa vida. Pero, al mismo tiempo, esta utopía residual se fusiona con un elemento homonormativo emergente, la necesidad de llevar una vida homosexual que emule la heterosexualidad y, sobre todo, la familia heterosexual burguesa.

Como parte de este conflicto entre vida promiscua y vida normalizada, entre Frank y Bern, hay que tener en cuenta que la película representa a los personajes también de forma binaria. Bern, quien no puede aceptar que Frank tenga relaciones casuales con otros hombres, es quien lo espera con la cena, quien se ocupa de la casa y el que quiere una relación monogámica. Según Jones, Bern se identifica con el rol de género femenino ( $«$ female-identified gender role») ${ }^{33}$. Por otro lado, es importante mencionar a otro personaje, Wally, una chica trans que aparece para reflejar también un modo de vida burgués de clase alta. Junto a ella, todos tienen nombres en femenino; así, por ejemplo, Frank es Peggy, ese es su Tuntennamen. Sin embargo, es ella también la que interroga a Bern respecto de los roles sexuales que tienen en la vida íntima, más específicamente pregunta quién es el hombre en la relación, para referirse al rol activo en la vida sexual, pero también al que ocupa el hombre en una relación, como si una pareja homosexual igualmente supusiera roles binarios y patriarcales como una heterosexual.

\section{Pedofilia y contagio}

Durante la visita de Wally, Frank tiene que dar una clase particular a un niño, Holgen. Es interesante esta escena porque el montaje nos muestra, por un lado, la clase particular de Frank y, por otro, lo que Wally y Bern hacen mientras tanto, quienes conversan, primero, y miran un cortometraje sobre los peligros de la pedofilia, después. En ese momento se genera un contrapunto entre lo que ocurre con la clase de Frank y la película que Bern y Wally miran. Taxi al W.C. incorpora así mediante found footage ${ }^{34}$ partes de un cortome-
[32] James Jones, «History and Homosexuality», p. 347. (La traducción es mía).

[33] James Jones, «History and Homosexuality», p. 347.

[34] La técnica cinematográfica del found footage - cuya traducción literal sería «metraje encontrado»-tiene una amplia difusión en la cultura cinematográfica masiva actual, principalmente como un subgénero dentro del cine de terror. Se trata de las películas que simulan ser un una cinta o videotape casero encontrado. Sin embargo, el término también tiene otra significación que proviene del uso experimental de metrajes e imágenes como una técnica en el cine equivalente al collage en las artes plásticas. Es decir, se trata de la composición de un filme a partir de fragmentos de otros filmes encontrados o la inserción, dentro de una película, de fragmentos de otras. Abigail Child, «Statement», en Cecilia Hausheer y Christoph Settele (eds.), Found Footage Film (Luzern, VIPER/zyklop, 1992), pp. 93-101. 
[35] James Jones, «History and Homosexuality», p. 342.

[36] James Jones, «History and Homosexuality», p. 343 (La traducción es mía).

[37] Según Haunss, Rosa Flieder fue el más importante periódico no comercial del movimiento Schwul de Núremberg, en el que entre 1979 y 1989 salen cincuenta y siete artículos escritos por activistas sobre temas específicos sobre la comunidad. Sebastian Haunss, «Von der sexuellen Befreiung zur Normalität. Das Ende der Zweiten deutschen Schwulenbewegung», en Andreas Pretzel y Volker Weiß (eds.), Rosa Radikale. Die Schwulenbewegung der 1970er Jahre (Hamburgo, Männerschwarm Verlag, 2012), p. 203.

[38] Sebastian Haunss, "Von der sexuellen Befreiung», p. 204.

[39] Sebastian Haunss, "Von der sexuellen Befreiung», p. 207.

[40] Paul B. Preciado, «Terror anal», p. 165 .

[41] Paul B. Preciado, «Terror anal», p. 170 .

[42] Paul B. Preciado, «Terror anal», p. 170 . traje didáctico homofóbico de los años cincuenta, la película Christian und sein Briefmarkenfreund, que se distribuyó en las escuelas ${ }^{35}$. Representaba un caso bastante evidente de abuso infantil en el que un homosexual intenta tener sexo con un niño, Christian. Mientras tanto, la situación entre Frank y Holgen es la inversa: Frank solo quiere enseñarle las lecciones, pero parece ser el niño el que juega con Frank y se le sienta encima. Mediante el montaje lo que se hace es contrastar las dos situaciones: una sobre los peligros de la pedofilia que, de manera homofóbica, da cuenta del peligro de la homosexualidad y de que los niños estén cerca de personas homosexuales. El segundo, el caso de Frank, es completamente opuesto: a pesar de llevar adelante una vida promiscua como homosexual, es profesional en su trabajo y su sexualidad no tiene nada que ver con la pedofilia. En ese sentido, como comenta Jones, «a través del uso de esta película "educativa" del pasado y la técnica de found footage, Ripploh crea una distancia irónica del estereotipo que socava ese mito» ${ }^{36}$. Es interesante pensar que el tema de las relaciones intergeneracionales era muy importante en esta época. Sebastian Haunss analiza el periódico Schwul Rosa Flieder ${ }^{37}$ entre 1979 y 1989 y encuentra que los dos temas principales en el seno de la comunidad Schwul alemana de esa época eran, por un lado, el VIH-SIDA y, por otro, los alcances de la pedofilia. La discusión pivoteaba, sobre todo, alrededor del parágrafo 175 del código penal y las diferencias que establecía entre la sexualidad hetero y la $S c h w u l$, es decir, cómo esta última constituía un mayor peligro para la juventud ${ }^{38}$. El tema, sin embargo, cae en el silencio después de la aparición del VIH-SIDA ${ }^{39}$.

La pedofilia sigue siendo hoy en día un tema muy controvertido y silenciado incluso dentro de los estudios queer. Lo que es interesante pensar para los años setenta y ochenta es que la novedosa aceptación y despenalización de la homosexualidad traía aparejado el hecho de convertirla en un nuevo peligro. La visibilidad homosexual implicaba la posibilidad de contagio y, por eso, era necesario mantenerla alejada de la juventud: «El niño aparece aquí como un artefacto biopolíticamente construido que permite la producción y normalización del adulto", sostiene Preciado ${ }^{40}$, quien menciona para el caso de Francia la publicación en 1973 de un número de la revista Recherches, que luego fue prohibido, en donde se abordaba el tema. Pero aclara que no se trataba de "un movimiento de adultos que buscan "proteger" a los menores de los peligros de la sexualidad o de "iniciarlos" al placer», sino, por el contrario, de «un movimiento de menores que buscan redefinir los límites de su cuerpo, hablar de su propia sexualidad, tomar decisiones acerca del placer y de los modos de producirlo y regularlo» ${ }^{41}$. Preciado cita, incluso, la propia revista en donde los que toman la voz son los jóvenes que se autodefinen como «movimiento de liberación [que] es también un movimiento de menores contra los pederastas adultos» ${ }^{42}$. Fue quizá René Schérer quien más desarrolló un cuestionamiento sistemático al concepto de pedofilia, lo que lo llevó a tener problemas judiciales y a que sus producciones no pudieran ser reeditadas durante mucho tiempo. En sus libros Émile perverti ou Des rapports entre l'éducation et la sexualité 
(1974) y en Co-ire, album systématique de l'enfance (1976), en colaboración con Guy Hocquenghem ${ }^{43}$, desarrolló duras críticas al sistema educativo y la represión de la sexualidad. Para Schérer, quien tuvo una relación con el joven Hocquenghem cuando fue su alumno, la verdadera perversión era la de los adultos que censuran y reprimen cualquier atisbo de sexualidad infantil.

Por otro lado, en una entrevista de 1978, Foucault se refiere a que las leyes ya no castigan una infracción, sino que protegen a ciertos sectores de la población a los que considera "particularmente frágiles ${ }^{44} \mathrm{y}$ habla de todo un saber psiquiátrico y psicológico que considera a la sexualidad como un peligro:

Y la sexualidad ya no será una conducta con ciertas prohibiciones precisas, va a convertirse en una suerte de peligro que merodea, una suerte de fantasma omnipresente, un fantasma que va a jugarse entre hombres y mujeres, entre niños y adultos y eventualmente entre los propios adultos. La sexualidad va a convertirse en esa amenaza en todas las relaciones sociales, todas las relaciones de edad, todas las relaciones de individuos [...]. Habrá con ello todo un nuevo régimen de control de la sexualidad. Sin embargo, el hecho de que en la segunda mitad del siglo XX se la descriminalice, es cierto, pero para aparecer bajo la forma de un peligro universal, es un cambio considerable. Yo diría que ahí está el peligro45.

En el fondo de esta discusión, podemos observar cómo la homosexualidad, una vez despenalizada (aunque parcialmente), es convertida ahora en una enfermedad contagiosa - como ocurriera en épocas anteriores, sobre todo durante el nacionalsocialismo-, de la que hay que protegerse, mucho más que de la sexualidad heterosexual. Si bien esto no es nuevo, sino que se trata de los sentidos social y biopolíticamente atribuidos a la homosexualidad que perduran de forma residual, es también posible vincularlo con los cambios parciales en las leyes de criminalización de la homosexualidad. Las relaciones heterosexuales eran legales para mayores de catorce; en cambio, con la despenalización de 1969, las relaciones homosexuales dejaron de ser penadas para personas mayores de dieciocho años. La homosexualidad seguía teniendo una carga mayor de «contagio». Una relación heterosexual consentida de un hombre mayor con una niña de catorce años estaba permitida, pero una homosexual de un hombre, por ejemplo, de diecinueve con uno de diecisiete seguía siendo perversa, porque de lo que se trataba era de proteger a los menores ${ }^{46}$.

\section{Found footage y pornografía}

La inclusión de fragmentos de la película Christian und sein Briefmarkenfreund en Taxi al W.C. no es el único uso del found footage. Resulta interesante mencionar un momento en el que Frank está viendo en televisión una entrevista a dos neonazis que proponen campos de trabajo o reeducación para asociales y homosexuales. De esta forma se conecta el presente de liberación de los años ochenta con la continuación de la ideología nacional socialista en el seno del régimen patriarcal. Como afirma Jones, «aunque ninguno de los
[43] René Schérer, Émile perverti ou Des rapports entre l'éducation et la sexualité (París, Robert Laffont, 1974). Guy Hocquenghem y René Schérer (eds.), Co-ire, album systématique de l'enfance (Revue Recherches, n. ${ }^{\circ} 22$, abril, 1976).

[44] Michel Foucault, «La ley del pudor» en Sexualidad y política. Escritos y entrevistas 1978-1984 (Buenos Aires, El cuenco de plata, 2016), p. 56-7.

[45] Michel Foucault, «La ley del pudor», p. 63.

[46] Clayton Whisnant, Male Homosexuality in West Germany: Between Persecution and Freedom 1945-69 (Londres, Palgrave Macmillan, 2014), p. 200-201. 
[47] James Jones, «History and Homosexuality», p. 348. (La traducción es mía).

[48] Richard Dyer, Now You See It, p. 214. (La traducción es mía).

[49] James Jones, «History and Homosexuality», p. 344. (La traducción es mía).

[50] Dirigida por William Friedkin, A la caza tiene de protagonista a $\mathrm{Al}$ Pacino después del éxito y repercusión de $E l p a$ drino (The Godfather, Francis Ford Coppola, 1972) y de El padrino: Parte II (The Godfather: Part II, Francis Ford Coppola, 1974), lo que la convierte en una película muy taquillera y, con eso, en un importante dispositivo de disciplinamiento de la sexualidad. La película muestra la cultura SM-leather gay de Nueva York de una forma sórdida y degradante con la que asocia, además, una serie de asesinatos, producto también de la supuesta violencia propia de ese ambiente. Junto a la ya mencionada Die Konsequenz, podemos considerarlas películas claramente disciplinadoras y que se basan en mostrar los peligros de llevar adelante una vida homosexual.

[51] James Jones, «History and Homosexuality», p. 344. personajes realiza la conexión entre el pasado y el presente - entre el pasado nacionalsocialista y la reapropiación del pasado en el presente- el espectador está destinado a hacerlo»47. Así, podemos pensar este detalle como la otra cara de la liberación, la homofobia continúa y podemos preguntarnos hasta qué punto este lazo con la persecución nazi a los homosexuales no se puede vincular con la visión más normalizadora de la homosexualidad, la de formar una pareja monogámica siguiendo el modelo de la familia heterosexual, como forma de ser aceptado, de normalizarse para evitar la persecución a la disidencia, todavía vigente o latente.

Pero no son los únicos montajes con imágenes de archivo, de otras películas o de la televisión. En un momento se intercalan fotogramas de segundos de películas pornográficas heterosexuales vintage, probablemente de la década del veinte o treinta. El porno vintage heterosexual se entromete en el encuentro con los profesores en el bowling para dar cuenta del grado de heteronormatividad del encuentro, de los prejuicios o, como comenta Dyer, para sugerir «la insistencia ubicua de la sexualidad», así como el hecho de que el deseo heterosexual no es menos bajo y promiscuo que el homosexual ${ }^{48}$. En esta escena, además, vemos cómo los profesores de la escuela hablan con sospecha de la vida privada de Frank y encontramos opiniones como la del profesor de religión que considera que la reciente Jesucristo superstar (Jesus Christ Superstar, Norman Jewison, 1973) guía por el buen camino a los jóvenes en tiempos de desviación moral. Pero también, según Jones, lo que hace este uso del found footage es «forzar al espectador a cuestionar las modernas definiciones del término "pornográfico"»49, para negar el mito que define cualquier película de temática gay como pornográfica.

Por otro lado, este uso de found footage por parte de Ripploh nos remite nuevamente al uso de pornografía gay en una película muy taquillera del mismo año, A la caza de William Friedkin ${ }^{50}$. En este filme, también de 1980, las escenas de asesinato están intercaladas con fotogramas casi imperceptibles de pornografía gay, específicamente de penetración anal, que se asocia a la penetración del cuchillo asesino en la víctima. Este uso en $A$ la caza es claramente homofóbico y se vincula con la asociación de la sexualidad gay con lo oscuro, lo bajo, lo degradado, lo peligroso y la delincuencia. Cada vez que el asesino clava su cuchillo vemos, por fragmentos de segundo, fotogramas de penetración anal gay. En Taxi al W.C., por el contrario, son escenas de pornografía heterosexual las que se intercalan en las charlas con otros docentes. Sin embargo, el porno gay sí aparece representado en la película de Ripploh, pero en las repetidas referencias a Tom de Finlandia. Sus dibujos pornográficos están colgados en las paredes de Frank, aparecen en las revistas que este lee e, incluso, en una remera que este usa. Según Jones, la película de Ripploh debe ser entendida como una redefinición de la imagen del cuerpo masculino que tuvo lugar en los setenta y principios de los ochenta ${ }^{51}$. En este sentido, los cuerpos desnudos no son los mismos cuerpos idealizados del porno gay de los setenta que podemos ver en los dibujos de Tom de Finlandia. 
Asimismo, la película lleva adelante un juego de citación y distancia paródica respecto a la retórica de la pornografía audiovisual. Por ejemplo, el primer encuentro con Bern rompe las expectativas del espectador de porno gay. Después de conocerse van a casa de Frank en un encuentro casual, pero allí donde la retórica pornográfica implica que el espectador espere una escena sexual, Ripploh nos ofrece una escena muy romántica en la bañera. El hecho de que Frank se oponga a la monogamia no lo convierte en un estereotipo de deseo sexual desenfrenado como las figuras del porno, sino que hay ternura y vida en común. Más que reproducir la lógica de la familia heterosexual, hay un intento por producir nuevas formas de relacionarse ${ }^{52}$. Este uso de las expectativas de la pornografía también lo encontrábamos en la escena en el glory hole, en donde Frank corrige los trabajos de sus alumnos en vez de entregarse al sexo casual. Luego, cuando, ya en la cama, Frank y Bern están por tener sexo, son interrumpidos por el pedido de auxilio de una mujer que les toca el timbre. Se trata de una víctima de violencia de género. Ellos la contienen, la cuidan y la asisten. La misma bañera en la que se bañaron de forma romántica es en la que ahora limpian y curan a una mujer golpeada que toca a su puerta en busca de ayuda.

Este contrapunto entre la sexualidad explícita y disidente y la ruptura con las expectativas que genera la retórica del porno mainstream nos permite pensar también que Taxi al W.C. tiene una dimensión postpornográfica, antes de que este concepto comience a ser utilizado a mediados de los años ochenta ${ }^{53}$. Me interesa en este sentido mencionar una de las escenas en la que sí hay sexo explícito. Frank tiene relaciones con un viejo conocido de los baños públicos, con quien se reencuentra justamente allí. Esta escena también tiene elementos del BDSM: de hecho, a Frank le pegan con un cinto en las nalgas, consumen cocaína y Frank le practica lluvia dorada.

La escena de lluvia dorada está filmada de tal forma que demuestre que se trata de una práctica real, como si fuera un registro documental o como si se acudiera a la retórica del porno, que tiene que demostrar que el sexo que se está viendo en la pantalla no es fingido, actuado. Esto en el cine porno ocurre con lo que se conoce como cum-shot, la escena de la eyaculación. Pero en el caso mencionado de Ripploh la cámara expone a su compañero sexual siendo orinado en la cama. El movimiento de la cámara sin cortes muestra que se trata de Frank y no de una simulación, no de un montaje. ¿Por qué es importante que estas escenas sean reales? ¿Se trata, como en la pornografía, de lograr un efecto de realidad para el placer masturbatorio del espectador? Es interesante notar que en el montaje se yuxtapone este encuentro sexual con una charla de Frank con una colega de la escuela sobre banalidades. Es probable que lo explícito de las escenas de sexo redunde en una importancia política considerable que hace al lugar de enunciación de la película. Ripploh, personaje autoficcional, disfruta de su cuerpo y su sexualidad promiscua al tiempo que también lo hace el Ripploh actor, director y guionista, persona real.

La representación de prácticas sexuales BDSM también se puede contrastar con la película antes mencionada $A$ la caza, en la que se exhiben este tipo
[52] Michel Foucault, «De la amistad como forma de vida», en Sexualidad y política. Escritos y entrevistas 1978-1984 (Buenos Aires, El cuenco de plata, 2016), p. 87.

[53] El postporno surge en el contexto de las discusiones en el seno del feminismo a mediados de los ochenta, que se conocen como «feminist sex wars». La disputa pivoteaba alrededor de la posibilidad de prohibición de la pornografía o de la reapropiación de la misma. En ese sentido, el postporno es una forma de reapropiarse del porno, de sus retóricas, de sus técnicas, etc. para producir un tipo de pornografía que, por un lado, no someta a la mujer y, por otro, desafíe y ponga en duda nuestras concepciones binarias del género y la sexualidad. Se trata de deconstruir, asimismo, los mecanismos tradicionales por los cuales el porno heteropatriarcal construye el cuerpo de la mujer y no solo de la mujer, sino también la masculinidad como superior y dominante. Más que prohibir o censurar la pornografía (lo que aumentaría su significación y su poder), en el postporno se trata de anular el efecto disciplinador del porno heteronormativo, poniéndolo de manifiesto. Para un análisis más detallado de las discusiones no solo en torno a la pornografía, sino también en torno a prácticas disidentes como el BDSM en la cultura lésbica durante las «feminist sex wars». Atilio Rubino, «El (BD)SM como práctica política: disidencia y normalización en Sade, Sacher-Masoch y Monika Treut», en José Amícola (ed.), Una erótica sangrienta: literatura y sadomasoquismo (La Plata, Edulp, 2016), pp.189-220. 
de prácticas sexuales mediante un registro documental de los lugares de socialización leather. Pero en A la caza no solo no hay sexo explícito, sino que estas escenas tienen un carácter marcadamente diferente, tendiente a la patologización de la disidencia. Foucault cuestiona la vinculación del SM con una violencia reprimida. Para él se trata de prácticas de producción de placer que son consensuadas, no de un acto de violencia ${ }^{54}$. En este sentido, es interesante pensar una escena de $A$ la caza en la que interrogan a un posible sospechoso de los asesinatos. De forma bastante inentendible, en la sala de interrogatorios ingresa un hombre negro, grande y musculoso vestido solo con un jockstrap, que es el encargado de golpear al sospechoso de forma marcadamente violenta, para que admita asesinatos que sabemos que no cometió. Se solapan así dos formas de entender las prácticas BDSM, ya que se trata de un claro abuso del poder policial, pero resulta incongruente que la persona encargada de ejercer la violencia no sea uno de los policías, sino que encarne el estereotipo de amo BDSM, propio de la comunidad leather. Son dos formas, también, de concebir el poder, que aparecen confundidas de forma claramente homofóbica.

La cultura SM-leather, desde esta perspectiva, vuelve a posicionar a la disidencia sexual en el lugar de una enfermedad de la que hay que mantenerse alejado por el riesgo al contagio, de la violencia reprimida subyacente en esas prácticas. Según Foucault, las prácticas BDSM constituyen un modo de resistencia, de creación de placeres novedosos que no va en busca del descubrimiento del deseo, de la verdad esencial e identitaria del deseo. En A la caza esta forma de poder-resistencia creativo, propio de la comunidad SM-leather de la que habla Foucault, se solapa con el ejercicio del poder violento y coercitivo. En efecto, las prácticas BDSM son consensuadas, pero el sospechoso aquí es torturado y humillado sin que medie un código compartido. Es un ejercicio del poder desigual. No hay un consenso, no hay posibilidad de cambiar de roles. En A la caza estas dos formas de sadismo parecen tratarse de lo mismo, efecto generado por el hecho de que el policía que se encarga de pegarle esté en jockstrap y represente una posible fantasía de macho dominador. Se trata de una representación de las prácticas BDSM de la época completamente diferente a la de Ripploh en Taxi al W.C.

\section{Enfermedad, promiscuidad y disidencia}

[54] Michel Foucault, «Michel Foucault, una entrevista: Sexo, poder y la política de la identidad» en Sexualidad $y$ política. Escritos y entrevistas 1978-1984 (Buenos Aires, El cuenco de plata, 2016), pp. 203 у 209-210.
Si bien el VIH-SIDA se da a conocer recién un año después, en 1981, ya aparecen en la película de Ripploh algunas de las connotaciones que esta enfermedad va a adquirir, relacionada no solo con la homosexualidad, sino también con la vida promiscua, propia de la comunidad gay según la perspectiva conservadora que la convirtió, en sus primeros años, en la peste rosa. En Taxi al W.C. aparecen como una amenaza las enfermedades de transmisión sexual y, asimismo, como ocurriría con el VIH-SIDA años después, se representa a sus víctimas como culpables por el tipo de vida que llevan. Recordemos, por ejemplo, las frases de la Madre Teresa de Calcuta que en una entrevista con Russ 
Barber considera que el VIH-SIDA fue enviado por Dios «para abrir los ojos de la gente, y, muy a menudo, con sufrimientos como este, la gente se da cuenta de que no está bien lo que están haciendo y eso les lleva a pedir perdón a Dios y al prójimo ${ }^{55}$. También en $A$ la caza, la homosexualidad era una enfermedad que podía ser contagiosa. El policía interpretado por Al Pacino, que se infiltra en el ambiente SM-leather para buscar a un asesino de homosexuales, en contacto con ese entorno corre riesgo de perder su heterosexualidad. El final de la película sugiere que, una vez atrapado al culpable, las muertes continúan. El nuevo asesino podría ser el mismo $\mathrm{Al}$ Pacino, quien, antes que aceptar su deseo homosexual, prefiere matar a su objeto de deseo, matar la peste contagiosa de la homosexualidad.

En Taxi al W.C. Ripploh tiene una extraña enfermedad, va al médico y allí le revisan el ano en busca de una infección. En la sala de espera conversa con una prostituta que cuenta que ella practica fellatios sin condón, lo que puede hacer que se contagie algunas enfermedades. Luego, hacia el final de la película, Ripploh termina siendo internado en un hospital. Aunque en ningún momento se aclara qué tiene, allí Bernd le echa en cara que se la pasa de baño en baño y de sauna en sauna y le reclama que espera que haya aprendido la lección. Desde la visión de Bern -y de la sociedad homofóbica- la promiscuidad lo convierte en culpable de la enfermedad. De esta forma, se puede pensar que se anticipa a lo que ocurriría también -en el sentido común construido biopolíticamente- con la epidemia del VIH-SIDA pocos años más tarde. Ese sentido de la homosexualidad como una enfermedad y de la promiscuidad como causante de enfermedades de las que el enfermo es culpable ya estaba circulando antes de que estalle la crisis del VIH-SIDA en los ochenta. No solo vincula la sexualidad disidente con la posibilidad de contagio de ciertas enfermedades, sino que la misma sexualidad, el deseo sexual, es una enfermedad posible de contagiar. Esto es lo que puede verse en la película homofóbica sobre la pedofilia Christian und sein Briefmarkenfreund. Como afirma Gabriel Giorgi,
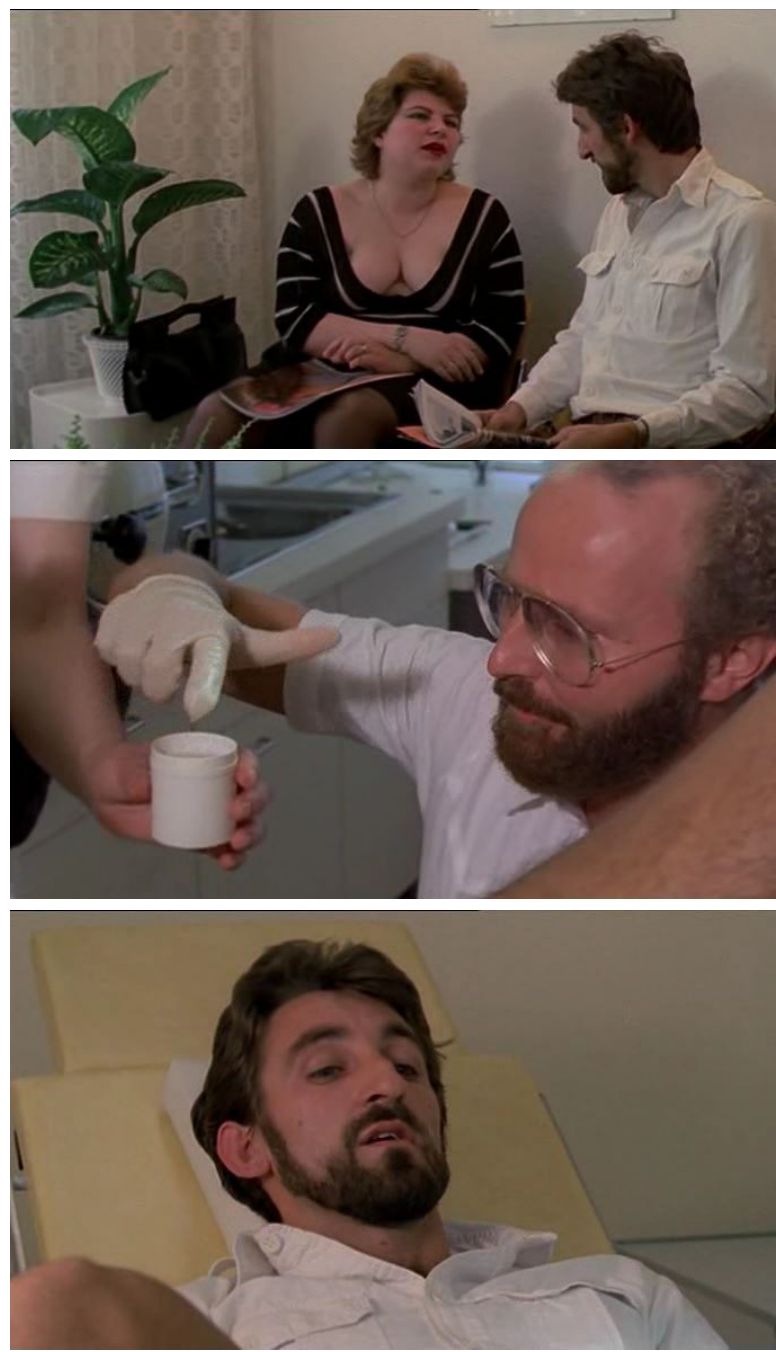

Frank en la consulta médica por una enfermedad no especificada, producto de su vida sexual activa, por lo que le revisan el ano. Fotograma de Taxi al W.C. 
[56] Gabriel Giorgi, Suenfios de exterminio: homosexualidad y representación en la literatura argentina contemporánea (Rosario, Beatriz Viterbo Editora, 2004), pp. 16-7. la solidaridad retórica entre homosexualidad e imaginación del exterminio no sorprende: la homosexualidad ha sido tradicionalmente asociada con la extinción de linajes, con el final de las familias y las progenies, la crisis del orden reproductivo, tanto biológico como cultural [...]. Enfermedades diversas y letales, desde la sífilis al sida, se asocian a la homosexualidad como un azote merecido en los espectáculos que los medios masivos montan en torno a ella. Sucesivas diagnosis culturales sobre sus perturbaciones psicológicas han hecho de los homosexuales una raza propicia de serial killers en ficciones literarias y cinematográficas ${ }^{56}$.

En Taxi al W.C. hay una variedad de prácticas disidentes que se tensionan con este sentido de la homosexualidad $-\mathrm{y}$, particularmente, de la promiscuidad Schwul- como una enfermedad: prácticas BDSM, lluvia dorada, glory holes, sexo callejero y la fiesta drag del final, entre otras. Además, todas ellas son mostradas con una explicitud que remite a la pornografía - aunque, como ya se dijo, también genera una torsión respecto a la retórica propia del cine pornográfico gay de la época-. Me interesa mencionar en particular una última escena de sexo casual de Frank. Cuando va al cajero automático, ve a un Leder, un gay con ropas de cuerpo, similares a las que podemos ver también en la película $A$ la caza. Es quizá una de las escenas más explícitas sexualmente. La conquista se da mediante miradas y luego van a la casa de Frank y allí tienen sexo, que incluye la práctica de lo que se

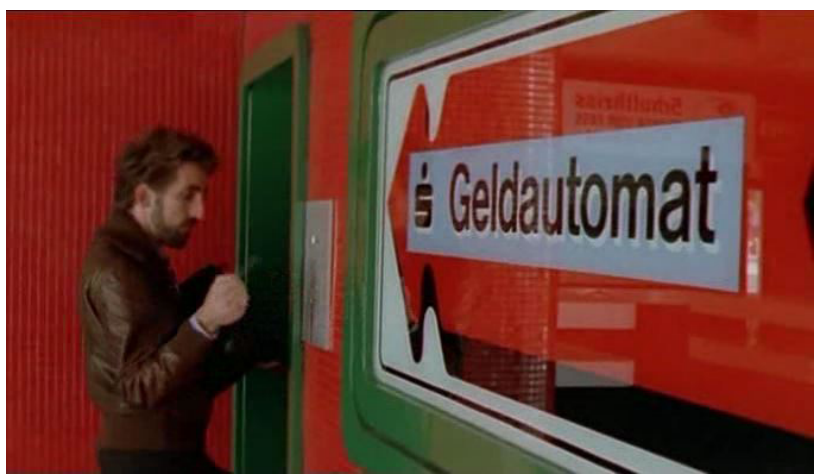
conoce como 69, luego Frank lo penetra y el Leder, cuyo nombre obviamente desconocemos, eyacula mientras es penetrado, y Frank lame de su vientre y pecho el semen. Se trata de prácticas que luego serán consideradas como no seguras. Pero me interesa aquí pensar que el encuentro se da, justamente, en un cajero automático, como un modo simbólico de referencia a todo un sistema capitalista de control de cuerpos y vidas. En este contexto, la sexualidad promiscua $-\mathrm{y}$ el placer, en general- se convierte en un gasto improductivo. Se trata de una producción anticapitalista del placer, un resto, en el seno del capitalismo simbolizado por el cajero.

\section{Contagio resignificado}

La película de Ripploh no intenta representar la verdad sobre todos los homosexuales, sino que bucea en la construcción histórica -tendríamos que 
decir también farmacopornográfica ${ }^{57}$ - de la homosexualidad como categoría: «La película genera y negocia lazos entre el estereotipo y el mito, entre la corrección política y el conservadurismo político, al negarse a plantear una solución como la única respuesta posible para todos los gays»..$^{8}$ En ese sentido es interesante indagar también en algunas cuestiones relacionadas con la corporalidad. En un momento Frank está viendo en la televisión un programa de ejercicios para mantenerse en forma. Se trata quizá, si lo pensamos en clave farmacopornográfica, de una forma de marcar que los cuerpos desnudos y explícitos que vemos en la pantalla no son tampoco los cuerpos del porno, aquellos musculados para generar placer visual ${ }^{59}$.

Este detalle menor adquiere interés porque justo en la escena siguiente Frank está enseñando anatomía en la escuela y pide a sus alumnos que le den una mirada al cuerpo humano, mientras desarma una figura del cuerpo de tamaño natural a la que le va sacando los órganos y los pasa a sus alumnos para que los analicen preguntando qué parte es cada una y cuál es su función. Aparece así una concepción del cuerpo medicalizada, producto de un saber/poder hegemónico que indica que cada parte tiene una función. En este sentido, podríamos preguntarnos, con Paul B. Preciado, «¿Es el ano un órgano sexual? Y en el caso de que lo fuera, ¿de qué sexo? ¿Y a qué sexualidad pertenecen las prácticas que lo implican?» ${ }^{60}$. La enfermedad que supuestamente tiene Frank por sus prácticas promiscuas también tiene que ver con lo anal. En la visita al médico, podemos ver que el órgano que se le revisa es el ano. Se trata de un uso del ano biopolíticamente vedado para el placer.

Las prácticas disidentes y promiscuas de Frank, el BDSM, la lluvia dorada, los baños, los glory holes, etc., tienden, en este sentido, a desarticular el cuerpo. Son producciones de placer sexual desgenitalizado. Constituyen una forma de hacerse un cuerpo sin órganos ${ }^{61}$ que desarticulan, en la práctica, la idea del cuerpo como organismo que se transmite hegemónicamente como saber aceptado en la escuela, en la ciencia, en lo discursivo. Práctica y discurso, producción y reproducción aparecen en una tensión no vislumbrada, que no se vive como tal. En un momento, Bernd escucha la radio y una oyente pregunta si una blusa de su hija que brilla en la oscuridad puede tener radiación, si puede afectar al organismo. En otro, Frank atiende a la madre de una de sus alumnas que tiene problemas de conducta en la escuela, y esta le comenta que le da Valium para tranquilizarla. Los cuerpos, en Taxi al W.C., aparecen observados desde lo farmacopornográfico, son cuerpos producidos por el biopoder.

Por otra parte, Ripploh le pone carne no solo a un personaje autoficcional, Frank Ripploh, docente y Schwul, sino que también su cuerpo es el que experimenta con la producción de nuevos placeres. De hecho el propio Ripploh trabajaba como profesor de una Hauptschule en West-Berlin ${ }^{62}$. Su
[57] Paul B. Preciado retoma el concepto de sociedades control de Deleuze, pero prefiere denominar farmacopornográfico al régimen actual de control de cuerpos y subjetividades, pues en él ya no se controla a los sujetos mediante la disciplina externa, sino que las tecnologías de subjetivación son internas, micro y protésicas, es decir, se convierten en cuerpo: «Si en la sociedad disciplinar las tecnologías de subjetivación controlaban el cuerpo desde el exterior como un aparato ortoarquitectónico extremo, en la sociedad farmacopornográfica, las tecnologías entran a formar parte del cuerpo, se diluyen en él, se convierten en cuerpo". Paul B. Preciado, Testo yonqui: sexo, drogas y biopolítica (Buenos Aires, Paidós, 2014), p. 72. Preciado ve al porno y la industria farmacológica como modelos utópicos de toda empresa: la lógica excitación/frustración del porno y la lógica de la medicina, ya no para curar enfermedades, sino para concebirlas, crearlas o, en realidad, construir lo humano, delimitar lo normal. Para Preciado, el control de la subjetividad se lleva adelante por un mecanismo microprotésico que es a la vez material (fármaco) y simbólicomediático (porno).

[58] James Jones, «History and Homosexuality», p. 348. (La traducción es mía).

[59] Se trata de la hipertrofia que Halperin considera como cuerpos «bizarros, hipertrofiados, incluso grotescos - es decir, queer- y, no obstante, intensamente deseables». David Halperin, San Foucault, p. 139.

[6o] James Jones, «History and Homosexuality», p. 348.

[61] Gilles Deleuze y Félix Guattari, Mil mesetas: capitalismo y esquizofrenia (Valencia, Pre-textos, 1988).

[62] Bernd-Ulrich Hergenmöller, Mann für Mann. Ein biographisches Lexikon (Frankfurt, Suhrkamp, 2002), p. 982. 

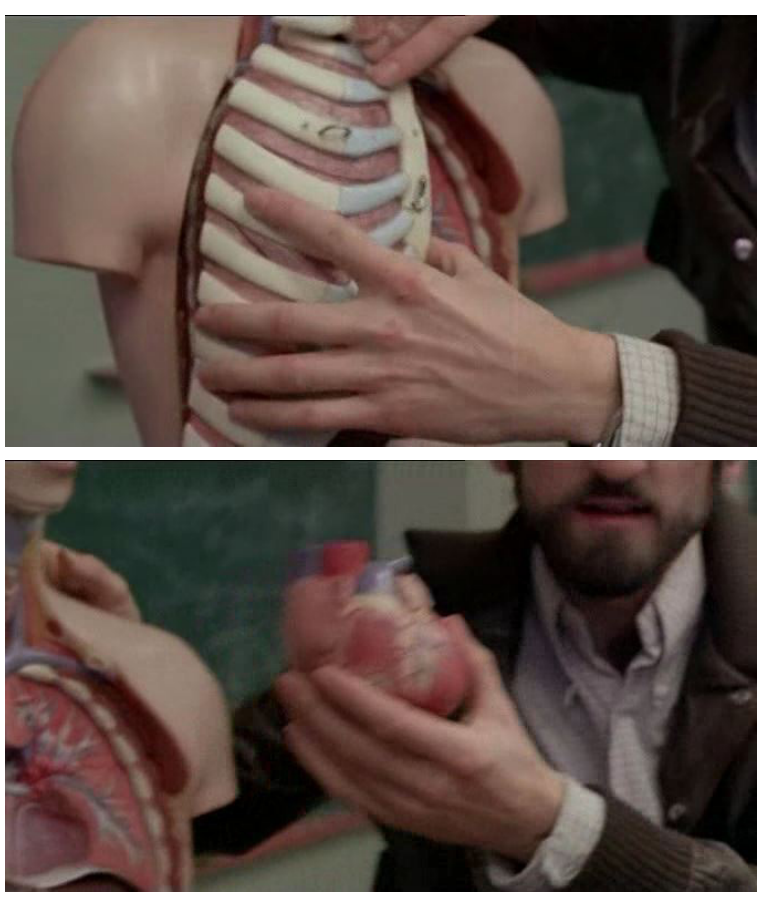

Frank enseñando anatomía en la escuela en la que ejerce como docente. Para el sistema disciplinador cada parte corporal tiene una única y delimitada función. Fotograma de Taxi al W.C. coming-out público fue en 1979 en la revista Der Stern ${ }^{63}$, en donde sale del armario junto a otros 682 hombres con el título Ich bin Schwul. Ello le trae una suspensión inmediata del trabajo y su expulsión definitiva en 1982, después del estreno de Taxi al W.C. Pero lo que es interesante es pensar aquí que se trata de una salida del armario que es estratégica, un gesto micropolítico de visibilización y legitimación de prácticas sexuales y formas de vida disidentes.

La película de Ripploh finaliza, justamente, con la salida pública del armario de Frank. Después de ir a una fiesta drag (Tuntenball) que dura toda la noche y de terminar su relación con Bernd, va directamente a la escuela a dar clases montado como Peggy von Schnottgenberg64. Una vez en la escuela, les propone a los alumnos como actividad para ese día que cada uno tome un dado y elija seis cosas que quieren hacer, pero no deben. Olvidando las reglas, tienen que rodar el dado y hacer lo que les toque en el número del uno a seis. Al final de la película vemos a Ripploh frente al espejo desmaquillándose y preguntándose en voz en off cuáles serían sus seis deseos para el dado. En este sentido, el final de la película, la consigna que Ripploh les propone a sus alumnos, constituye un punto de fuga a la producción de normalidad. O, habría que decir,

[63] Se trata de la nota con título «Ich bin Schwul» del número 41 de la revista Der Stern, de 1978, pp. 104-18. Como comenta Herzog, «A lo largo de esas líneas, cuando los activistas de la Nueva Izquierda Martin Dannecker y Reimut Reiche publicaron su estudio empírico masivo sobre las creencias y comportamientos de cientos de hombres homosexuales de Alemania Occidental, Der gewöhnliche Homosexuelle (El homosexual ordinario, 1974), sus hallazgos proporcionaron la la consigna que propone Peggy von Schnottgenberg. Según Richar Dyer, en este caso «el "dragueo" radical (hombres con vestidos, pero que no intentaban parecer mujeres) fue uno de los modos más confrontativos de la liberación gay y aquí incentiva la revuelta en contra del orden escolar» ${ }^{65}$. Muchas de las cosas que los chicos desean hacer constituyen un sinsentido: pegarle o romperle el velo al profesor, agujerear el sweater, gritar o decir una mala palabra. Se trata de puntos de fuga a la normalidad en el seno de uno de los dispositivos disciplinadores más potentes, el sistema educativo.

Me interesó pensar, en este sentido, cómo a comienzos de la década del ochenta, cuando la homosexualidad - ya no penada por la ley- comienza a ser supuestamente aceptada, se operan nuevos regímenes de opresión y de exclu-

base para que aparezcan informes comprensivos en los principales medios de comunicación». Dagmar Herzog, Sex after Fascism. Memory and Morality in Twentieth-Century Germany (Princeton, Princeton University Press, 2007), p. 154.

[64] Peggy von Schnottgenberg era el seudónimo que Ripploh usaba para sus trabajos como actor antes de la realización de Taxi al W.C., con el que participó en las películas Axel von Auersperg (1974) y Monolog eines Stars (1975), de Rosa von Praunheim y Betörung der blauen Matrosen (1975), y Madame X - Eine absolute Herrscherin (1978), de Ulrike Ottinger.

[65] Richard Dyer, Now You See It, p. 214. (La traducción es mía). 
sión que tienen que ver con la producción de lo humano. Ya no penada por la ley, dije, siempre que tengamos en cuenta la diferencia etaria legal que se establecía entre las relaciones hetero (catorce años) y las homosexuales (dieciocho años). Gayle Rubin considera que en la aceptación de ciertas vidas humanas e identidades hay una jerarquía de valores:

Las sociedades occidentales modernas evalúan los actos sexuales según un sistema jerárquico de valor sexual. En la cima de la pirámide erótica están solamente los heterosexuales reproductores casados. Justo debajo están los heterosexuales monógamos no casados y agrupados en parejas, seguidos de la mayor parte de los demás heterosexuales. El sexo solitario flota ambiguamente. El poderoso estigma que pesaba sobre la masturbación en el siglo XIX aún permanece en formas modificadas más débiles, tales como la idea de que la masturbación es una especie de sustituto inferior de los encuentros en pareja. Las parejas estables de lesbianas y gays están en el borde de la respetabilidad, pero los homosexuales y lesbianas promiscuos revolotean justo por encima de los grupos situados en el fondo mismo de la pirámide. Las castas sexuales más despreciadas incluyen normalmente a los transexuales, travestis, fetichistas, sadomasoquistas, trabajadores del sexo, tales como los prostitutos, las prostitutas y quienes trabajan como modelos en la pornografía y la más baja de todas, aquellos cuyo erotismo transgrede las fronteras generacionales ${ }^{66}$.

Podemos pensar la idea de la amenaza de la enfermedad homosexual -la homosexualidad como enfermedad y la promiscuidad Schwul como provocadora de enfermedades en castigo a la vida desviada - a partir de la figura del vampiro tomada de Deleuze y Guattari:

El vampiro no filia, contagia. La diferencia es que el contagio, la epidemia, pone en juego términos completamente heterogéneos [...]. Combinaciones que no son ni genéticas ni estructurales [...]. Nosotros sabemos que entre un hombre y una mujer pasan muchos seres, que vienen de otros mundos, traídos por el viento, que hacen rizoma alrededor de las raíces, y que no se pueden entender en términos de producción, sino únicamente de devenir. El Universo no funciona por filiación. Así pues, nosotros solo decimos que los animales son manadas, y que las manadas se forman, se desarrollan y se transforman por contagio ${ }^{67}$.

En este sentido, la disidencia puede convertirse en una enfermedad, pero resignificada, en una transmisión vampírica monstruosa que se opone a la filiación familiar. Como docente, Frank contagia a sus alumnos, pero no en el sentido homofóbico que se asocia a la homosexualidad en relación con los niños. Se trata de un contagio resignificado. Así, el contagio disidente - en vez de la filiación - contrarresta la producción de normalidad del capitalismo, que veíamos simbolizado en el cajero automático. De esta forma, también produce una inversión subversiva del insulto, un gesto queer que encontramos tanto en la salida del armario del propio Ripploh como del personaje autoficcional de su película que va a la escuela vestido como mujer. Es Peggy von Schnottgenberg quien en ese acto de visibilización parecería querer afirmar que no es
[66] Gayle Rubin, «Reflexionando sobre el sexo: notas para una teoría radical de la sexualidad», en Carole Vance, (ed.), Placer y peligro: explorando la sexualidad femenina (Madrid, Revolución, 1989), p. 136.

[67] Gilles Deleuze y Félix Guattari, Mil mesetas, p. 248. 
ni hombre ni mujer, que el sistema binario de sexo-género es una forma de la producción de cuerpos e identidades normales propia del capitalismo o del régimen farmacopornográfico.

La exhibición de su cuerpo y su sexualidad también nos dice que no es gay normal, no tiene el cuerpo que la maquinaria pornográfica le exige para formar parte del sistema. La revisión anal también nos indica qué partes del cuerpo pueden usarse para qué funciones en la maquinaria médica. Desde una perspectiva biopolítica esta producción de normalidad y abyección indica que siempre habrá un exterior que permita definir el adentro de lo humano, de lo normal y de lo aceptable. La monogamia, la familia, la respetabilidad y la discreción van a ser requisitos para esa aceptación de las vidas homosexuales. En esta clave intenté analizar Taxi al W.C. La aceptación de la homosexualidad genera jerarquías de valores según las cuales siempre habrá vidas que importen más que otras. La promiscuidad, la visibilidad y las prácticas disidentes como el BDSM se tensionan así con la posibilidad de aceptación social, que siempre implica una pérdida. En este sentido, la liberación disidente de los años setenta propició, también y paradójicamente, una pérdida de libertad, como harán notar una década después los Estudios Queer y su crítica a la normalización de lo gay-lésbico. Pero esto ya se estaba gestando en la década del setenta y se podía observar más claramente en el año bisagra entre la década de la liberación y la década de la emergencia de lo queer, 1980.

\section{Bibliografía}

Child, Abigail, «Statement», en Cecilia Hausheer y Christoph Settele (eds.), Found Footage Film (Luzern, VIPER/zyklop, 1992).

Deleuze, Gilles y Guattari, Félix, Mil mesetas: capitalismo y esquizofrenia (Valencia, Pre-textos, 1988).

Der Stern, «Ich bin Schwul» (Der Stern, n. ${ }^{\circ} 41,1978$ ), pp. 104-118.

Duggan, Lisa, The Twilight of Equality? Neoliberalism, Cultural Politics, and the Attack on Democracy (Boston, Beacon Press, 2003).

DYer, Richard, Now You See It: Studies on Lesbian and Gay Film (Londres/Nueva York, Routledge, 2007).

Foucault, Michel, «De la amistad como forma de vida», en Sexualidad y política. Escritos y entrevistas 1978-1984 (Buenos Aires, El cuenco de plata, 2016), pp. 87-93.

-, «La ley del pudor», en Sexualidad y política. Escritos y entrevistas 1978-1984 (Buenos Aires, El cuenco de plata, 2016), pp. 49-69.

-, «Michel Foucault, una entrevista: sexo, poder y la política de la identidad», en Sexualidad y política. Escritos y entrevistas 1978-1984 (Buenos Aires, El cuenco de plata, 2016), pp. 99-215.

-, «The Gay Science» (Critical Inquiry, n. ${ }^{\circ}$ 37, vol. 3, 2011), pp. 385-403.

Giorgi, Gabriel, Suenfios de exterminio: homosexualidad y representación en la literatura argentina contemporánea (Rosario, Beatriz Viterbo Editora, 2004).

HALPERIN, David, «The Normalization of Queer Theory» (Journal of Homosexuality, vol. 45, n. $\left.{ }^{\circ} 2-3-4,2003\right)$, pp. 339-343. 
HalPERIN, David, San Foucault: para una hagiografía gay (Buenos Aires, El cuenco de plata, 2007).

Haunss, Sebastian, «Von der sexuellen Befreiung zur Normalität. Das Ende der Zweiten deutschen Schwulenbewegung», en Andreas Pretzel y Volker Weiß (eds.), Rosa Radikale. Die Schwulenbewegung der 1970er Jahre (Hamburgo, Männerschwarm Verlag, 2012), pp. 199-212.

HERGENMÖLLER, Bernd-Ulrich, Mann für Mann. Ein biographisches Lexikon (Frankfurt, Suhrkamp, 2002).

Herzog, Dagmar, Sex after Fascism. Memory and Morality in Twentieth-Century Germany (Princeton, Princeton University Press, 2007).

Hocquenghem, Guy y Schérer, René (eds.), Co-ire, album systématique de l'enfance (Revue Recherches, n. $^{\circ}$ 22, abril, 1976).

Holy, Michael, «Jenseits von Stonewall - Rückblicke auf die Schwulenbewegung in der BRD 1969-1980», en Andreas Pretzel y Volker Weiß (eds), Rosa Radikale. Die Schwulenbewegung der 1970er Jahre (Hamburgo, Männerschwarm Verlag, 2012), pp. 39-79.

JAGose, Annamarie, Queer Theory: An Introduction (New York, New York University Press, 1996).

JoNES, James, «History and Homosexuality in Frank Ripploh's Taxi to the Toilet», en Christoph Lorey y John Plews, Queering the Canon: Defying Sights in German Literature and Culture (Columbia, Camden House, 1998), pp. 340-349.

Mira, Alberto, Miradas insumisas. Gays y lesbianas en el cine (Barcelona/Madrid, Egales, 2008).

O'Rourke, Chris, «Queer London on Film: Victim (1961), The Killing of Sister George (1968) and Nighthawks (1978)», en Pam Hirsch y Chris O'Rourke (eds.), London on Film (Basingstoke, Palgrave Macmillan, 2017), pp. 117-131.

Preciado, Paul B., «Terror anal: apuntes sobre los primeros días de la revolución sexual», en El deseo homosexual (con Terror anal) (Barcelona, Melusina, 2009), pp. 133-174.

-, Testo yonqui: sexo, drogas y biopolítica (Buenos Aires, Paidós, 2014).

Rubin, Gayle, «Reflexionando sobre el sexo: notas para una teoría radical de la sexualidad», en Carole Vance, (ed.), Placer y peligro: explorando la sexualidad femenina (Madrid, Revolución, 1989), pp. 113-190.

RuBino, Atilio Raúl, «El (BD)SM como práctica política: disidencia y normalización en Sade, Sacher-Masoch y Monika Treut», en José Amícola (ed.), Una erótica sangrienta: literatura y sadomasoquismo (La Plata, Edulp, 2016), pp. 189-220.

-, «Hacia una (in)definición de la disidencia sexual. Una propuesta para su análisis en la cultura», (Revista Luthor [entender, destruir y crear], n. ${ }^{\circ}$ 39, vol. IX, 2019), pp. 62-80.

Russo, Vito, The Celluloid Closet: Homosexuality in the Movies. Revisited Edition (Nueva York, Harper \& Row, 1995).

SÁEZ, Javier, «El contexto sociopolítico de surgimiento de la teoría queer. De la crisis del sida a Foucault», en David Córdoba, Javier Sáez y Francisco Vidarte (eds.), Teoría queer: políticas bolleras, maricas, trans, mestizas (Barcelona/Madrid, Egales, 2005), pp. 67-76.

SAXE, Facundo, Representación transnacional de las sexualidades disidentes en textos culturales alemanes recientes (1987-2012) (Tesis Doctoral, FaHCE-UNLP, 2014). 
SCHÉRER, René, Émile perverti ou Des rapports entre l'éducation et la sexualité (París, Robert Laffont, 1974).

WARnER, Michael, «Introduction», en Fear of a Queer Planet: Queer Politics and Social Theory (Minneapolis, University of Minnesota Press, 1993), pp. vii-xxxi.

Whisnant, Clayton, Male homosexuality in West Germany: Between Persecution and Freedom 1945-69 (Londres, Palgrave Macmillan, 2014).

Recibido: 19 de agosto de 2018

Aceptado para revisión por pares: 11 de enero de 2019

Aceptado para publicación: 21 de septiembre de 2019 
